\title{
Highly fermentable starch at different diet starch concentrations decreased feed intake and milk yield of cows in the early postpartum period
}

\author{
Rodrigo I. Albornoz and Michael S. Allen ${ }^{1}$ \\ Department of Animal Science, Michigan State University, East Lansing 48824
}

\begin{abstract}
The objective of this study was to evaluate the effects of diet starch concentration and fermentability $(\mathrm{SF})$ fed during the early postpartum (PP) period on dry matter intake (DMI), yields of milk and milk components, body reserves, and metabolism. Fifty-two multiparous Holstein cows were used in a randomized block design with a $2 \times 2$ factorial arrangement of treatments. Treatment diets were formulated to $22 \%$ (LS) or $28 \%$ (HS) starch with dry ground corn (DGC) or high-moisture corn (HMC) as the primary starch source. Treatments were fed from 1 to $23 \mathrm{~d} \mathrm{PP}$ and cows were switched to a common diet until $72 \mathrm{~d}$ PP to measure carryover (CO) effects. Treatment period (TP) diets were formulated for $22 \%$ forage neutral detergent fiber and $17 \%$ crude protein, and starch concentration was adjusted by substitution of corn grain for soyhulls. Throughout the experiment DMI and milk yield were measured daily, and milk components, body condition score (BCS), and body weight were measured weekly. Blood was collected weekly during the TP and every second week during the CO period. During the TP, HMC decreased DMI more when included in the HS $(3.9 \mathrm{~kg} / \mathrm{d})$ than in the LS $(0.9 \mathrm{~kg} / \mathrm{d})$ diets and HMC decreased yields of milk, fat, and FCM by $4.3,0.19$, and $4.8 \mathrm{~kg} / \mathrm{d}$, respectively. Treatments also interacted over time to decrease DMI and yields of milk and milk components more for HMC compared with DGC as time progressed during the TP. Loss of BCS was increased when HMC was fed in a HS diet $(-0.38$ vs. -0.17$)$ and decreased when included in a LS diet (-0.21 vs. -0.29$)$ with no effects on body weight change during the TP. Treatments interacted with time to affect plasma concentrations of glucose and insulin with HS increasing concentrations early in the TP compared with LS but with similar effects by the end of the TP. During the CO period, treatment effects on DMI diminished over time with no main effects of treatment for the entire period. Starch concentration
\end{abstract}

Received March 28, 2018.

Accepted June 3, 2018.

${ }^{1}$ Corresponding author: allenm@msu.edu and SF interacted to affect yields of milk, fat, and FCM during the $\mathrm{CO}$ period, which were greater for HS-DGC and LS-HMC (54.8 and 52.8, 1.76 and 1.81, and 51.3 and $52.2 \mathrm{~kg} / \mathrm{d}$, respectively) than for LS-DGC and HSHMC (51.2 and 51.0, 1.68 and 1.64, and 48.4 and 48.6 $\mathrm{kg} / \mathrm{d}$, respectively). Treatments did not affect BCS change during the $\mathrm{CO}$ period but HS lost body weight compared with LS ( -5.7 vs. $7.0 \mathrm{~kg}$ ). Blood glucose and insulin concentrations were not affected by treatments during the $\mathrm{CO}$ period. Feeding a highly fermentable starch source during the early PP period decreased DMI and yields of milk and milk components compared with a less fermentable starch source and the depression in DMI was greater when fed in the higher starch diet. However, diet starch concentration had no effects on yield of milk or milk components.

Key words: starch concentration, starch fermentability, hepatic oxidation theory

\section{INTRODUCTION}

Feed intake during the early postpartum (PP) period is often inadequate to support the rapid increase in energy required for milk production resulting in negative energy balance affecting health, production, and reproductive performance (Herdt, 2000; Butler, 2003; Ospina et al., 2010). Inadequate nutrition during early lactation resulted in a negative carryover effect on milk yield of 22 to $63 \%$ during the following 3 to $12 \mathrm{wk}$ for several studies reviewed by Jørgensen et al. (2016). Energy intake during the early PP period can be increased by substituting high-starch feeds for fiber sources with lower digestibility to a point beyond which rumen function is compromised or feed intake is depressed. Starch is an important source of fermentable energy for rumen microorganisms (Koenig et al., 2003) and supplies glucose and glucose precursors to the cow. However, few studies have investigated the effects of diet starch concentration during the early PP period, and these studies have yielded inconclusive results. Increasing diet starch concentration increased DMI in studies reported by Rabelo et al. (2003) and Andersen et al. (2003) but had no effect on DMI in studies reported by 
Nelson et al. (2011) and McCarthy et al. (2015a). In addition, ruminal fermentability of starch varies greatly with grain type, processing, and conservation method (Allen, 2000), but increased starch fermentability decreased DMI in one study (Sadri et al., 2009) and had no effect in another (Rockwell and Allen, 2016).

Conflicting results of previous studies reported in the literature evaluating effects of diet starch concentration and fermentability are likely from interactions among diet starch concentration and fermentability, diet forage NDF (fNDF) concentration and duration of treatments. Propionate from ruminal fermentation of starch is a primary glucose precursor needed to restore euglycemia, but propionate can also suppress feed intake (Oba and Allen, 2003a; Bradford and Allen, 2007), especially for cows in the $\mathrm{PP}$ period that are in a lipolytic state (Oba and Allen, 2003a; Piantoni et al., 2015a). This suppression of feed intake has been linked to the stimulation of fuel oxidation in the liver by propionate, with hypophagic effects likely aggravated during the early PP period when cows increase mobilization of body reserves and acetyl CoA available for hepatic oxidation is increased (Oba and Allen, 2003b; Stocks and Allen, 2012, 2013; Piantoni et al., 2015a).

Our objective was to evaluate the combined effects of diet starch concentration and fermentability for cows in the early PP period and their potential carryover effects on DMI, yields of milk and milk components, body reserves, and metabolism. The starch treatments were corn grain harvested as high-moisture (high ruminal fermentability) or dry (moderate ruminal fermentability). Starch concentration of diets were adjusted by substituting corn grain for soyhulls, keeping fNDF and the filling effect of diets constant. We hypothesized that rations with highly fermentable starch will decrease DMI and yields of milk and milk components by cows during the early PP period compared with rations with moderate starch fermentability, and effects will be greater for diets with greater starch concentration. We also hypothesized that treatment effects during the PP period will carryover once they receive a common diet but the effects will diminish over time.

\section{MATERIALS AND METHODS}

\section{Animal Care}

This study was conducted from February 1 to November 15, 2015, at the Dairy Cattle Research and Teaching Center at Michigan State University with all experimental procedures approved by the Michigan State University Institutional Animal Care and Use Committee (East Lansing, MI; AUF 11/13-254-00).
Cows were housed individually in tiestalls, allowing for daily records of feed offered and refused, and fed once a day $(0800 \mathrm{~h})$ at $115 \%$ of expected intake and milked at the parlor twice a day $(0400 \mathrm{~h}$ and $1430 \mathrm{~h})$. All cows were in apparent good health at the beginning of the experiment, and standard farm health and reproductive protocols were maintained during this study. Signs for ketosis (e.g., depressed feed intake and milk yield and change in normal behavior) were monitored daily and diagnosis was aided with the use of a urine ketone test (Ketostix, Bayern Corp., Elkhart, IN). Confirmed cases were administered $300 \mathrm{~mL}$ of propylene glycol for 3 to $5 \mathrm{~d}$.

\section{Experimental Design and Treatments}

Fifty-two multiparous Holstein cows were used in a completely randomized block design experiment with 2 $\times 2$ factorial arrangement of treatments with 13 cows per treatment. Blocking criteria consisted of BCS observed within 1 wk before expected calving date (up to 1 unit difference using a 5-point scale, where $1=$ thin and 5 = fat; Wildman et al., 1982), previous lactation 305 -d mature equivalent milk production (within 5,000 $\mathrm{kg}$ ) and date of parturition (within $60 \mathrm{~d}$ ). A common close-up diet was fed from $21 \mathrm{~d}$ before expected parturition date until calving. This diet contained corn silage, mature grass hay, dry ground corn, soybean meal, SoyChlor (West Central Soy, Ralston, IA), and a mineral and vitamin mix, and was formulated to contain $42.5 \%$ NDF, $38.3 \%$ fNDF, $21.5 \%$ starch, and $13.5 \%$ CP.

Treatments included diet starch concentration (SC; low starch $=22 \%, \mathbf{L S}$, or high starch $=28 \%, \mathbf{H S}$ ) and diet starch fermentability (SF; dry ground corn, DGC, or high-moisture corn, HMC). At calving, cows were randomly assigned to 1 of the 4 diet treatment combinations (LS-DGC, LS-HMC, HS-DGC, HS-HMC). Dry ground corn grain was stored in a covered gravity wagon and HMC was ground and ensiled in a bag (AgBag Plastic, Cottage Grove, MN) for at least 4 mo after harvest before utilization. Differences in SF were confirmed by 7 -h in vitro starch digestibility analysis before and throughout the experiment (Table 1) according to Goering and Van Soest (1970). Starch concentration of treatment diets was adjusted by partially replacing the main starch source with soyhulls to maintain the same fNDF concentration across treatment diets. Treatment diets contained alfalfa silage, grass hay, corn grain treatments, soyhulls, soybean meal, minerals, and vitamins and were formulated to $17 \% \mathrm{CP}$ and $22 \%$ fNDF (Table 2 ). Cows received their respective diets beginning at the day of calving if they calved before feeding time $(0800 \mathrm{~h})$ or at the following morning's feeding until $23 \mathrm{~d}$ 
Table 1. Nutrient composition, digestibility, and energy concentration of starch sources ${ }^{1}$

\begin{tabular}{lcc}
\hline Variable & DGC & HMC \\
\hline Nutrient composition, \% of DM & & \\
DM & 91.7 & 64.1 \\
OM & 98.9 & 98.5 \\
Starch & 72.7 & 73.4 \\
CP & 8.47 & 7.67 \\
NDF & 8.76 & 7.82 \\
Indigestible NDF & 3.46 & 3.65 \\
Ash & 1.12 & 1.48 \\
Starch digestibility $7 \mathrm{~h}^{2} \%$ & 44.1 & 61.9 \\
Gross energy, Mcal/kg & 4.34 & 4.36 \\
\hline
\end{tabular}

${ }^{1} \mathrm{DGC}=$ dry ground corn; HMC = high-moisture corn.

${ }^{2}$ Starch digestibility measured in vitro for $7 \mathrm{~h}$ as is.

$\mathrm{PP}$ with this period identified as the treatment period (TP). During the carryover period (CO) from 24 to $72 \mathrm{~d}$ PP, all cows received a common diet to evaluate possible residual effects of treatment diets (Table 2 ). Dry matter concentration of fermented feeds was determined twice per week throughout the experiment and diets were adjusted accordingly. All rations were formulated to meet or exceed cows predicted requirements for protein, minerals, and vitamins according to NRC (2001) and ingredient and nutrient composition of treatment and CO diets are described in Table 2.

\section{Data and Sample Collection}

Feed offered, orts, and milk yield were recorded on a daily basis throughout the experiment. Samples and measurements were collected or recorded on the same day of the week $\pm 3 \mathrm{~d}$ relative to expected calving date prepartum or relative to day of calving during the $\mathrm{PP}$ period. Backfat thickness (BFT), BCS, BW, feed ingredients, and PM milk samples were collected on the same day of the week $(5,12,19,26,33,40,47,54,61$, and $68 \mathrm{~d}$ PP), with AM milk and orts samples collected the following morning. An additional measurement of BFT and collection of blood sample was performed within a week before parturition, and BCS and BW were also determined at calving to be used as a covariate for statistical analysis. Representative samples $(0.5 \mathrm{~kg})$ of feed ingredients were collected weekly throughout the experiment and stored at $-20^{\circ} \mathrm{C}$ for later analysis of DM and nutrient composition. Milk samples were collected weekly at each milking and stored with preservative (Bronopol, D\&F Control Systems, San Ramos, $\mathrm{CA}$ ) at $4^{\circ} \mathrm{C}$ for component and SCC analysis (Universal Lab Services, East Lansing, MI). Body condition was scored by 3 trained investigators on a 5-point scale, as described by Wildman et al. (1982). Subcutaneous cross-section measurements of BFT were performed on

Table 2. Ingredient and nutrient composition of treatment and carryover $\operatorname{diets}^{1}$

\begin{tabular}{|c|c|c|c|c|c|}
\hline \multirow[b]{2}{*}{ Item } & \multicolumn{2}{|c|}{ LS } & \multicolumn{2}{|c|}{ HS } & \multirow{2}{*}{$\begin{array}{c}\text { Common } \\
\text { diet }\end{array}$} \\
\hline & DGC & $\mathrm{HMC}$ & DGC & $\mathrm{HMC}$ & \\
\hline \multicolumn{6}{|l|}{ Ingredient, $\%$ of $\mathrm{DM}$} \\
\hline Corn silage & - & - & - & - & 25.6 \\
\hline Alfalfa silage & 37.0 & 37.1 & 37.7 & 37.0 & 17.3 \\
\hline Grass hay & 8.25 & 8.35 & 8.35 & 8.21 & - \\
\hline DGC & 27.5 & - & 35.4 & - & 17.8 \\
\hline $\mathrm{HMC}$ & - & 28.1 & — & 36.2 & 9.30 \\
\hline Soyhulls & 11.0 & 11.0 & 1.87 & 2.18 & - \\
\hline Soybean meal & 11.7 & 11.1 & 12.2 & 12.4 & 15.3 \\
\hline Cottonseed & - & - & - & - & 7.2 \\
\hline Wheat straw & - & - & - & - & 4.47 \\
\hline Mineral-vitamin $\operatorname{mix}^{2}$ & 2.02 & 2.02 & 2.02 & 2.02 & 2.15 \\
\hline Limestone & 0.55 & 0.55 & 0.55 & 0.55 & 0.72 \\
\hline Sodium bicarbonate & 0.95 & 0.95 & 0.95 & 0.95 & 0.75 \\
\hline Dicalcium phosphate & 0.95 & 0.95 & 0.95 & 0.95 & - \\
\hline \multicolumn{6}{|c|}{ Nutrient composition, \% of DM } \\
\hline DM & 58.4 & 55.2 & 59.2 & 53.1 & 56.1 \\
\hline $\mathrm{OM}$ & 89.5 & 89.4 & 89.8 & 89.6 & 91.8 \\
\hline $\mathrm{NDF}$ & 33.0 & 33.0 & 28.3 & 27.6 & 28.1 \\
\hline Forage NDF & 22.4 & 22.8 & 22.6 & 22.2 & 20.4 \\
\hline $\mathrm{CP}$ & 17.2 & 16.7 & 17.3 & 16.9 & 16.9 \\
\hline Starch & 21.4 & 21.9 & 27.1 & 27.8 & 28.9 \\
\hline Ash & 10.5 & 10.5 & 10.2 & 10.3 & 8.18 \\
\hline Gross energy, Mcal/kg & 4.21 & 4.21 & 4.25 & 4.25 & $\mathrm{ND}^{3}$ \\
\hline
\end{tabular}


the right side of the cow between the 12th and 13th rib by ultrasonography (Aloka SSD-500V monitor and UST-5044-3.5 MHz probe, Aloka Co., Ltd., Tokyo, Japan). Backfat thickness was determined by performing an average of 2 measurements that were within $0.1 \mathrm{~cm}$ difference. Blood samples were collected via coccygeal venipuncture after orts collection and before feeding at $6,13,20,27,41,55$, and $69 \mathrm{~d}$ PP. Blood was collected in separate tubes containing potassium oxalate/sodium fluoride (for glucose analysis) and $\mathrm{K}_{2}$-EDTA (for all other analysis) and immediately spun (3,000 $\times g \times 15$ min at $5^{\circ} \mathrm{C}$ ) to harvest plasma, which was stored at $-20^{\circ} \mathrm{C}$.

\section{Sample Analysis}

Feed ingredients were dried in a $55^{\circ} \mathrm{C}$ forced-air oven for $72 \mathrm{~h}$, analyzed for DM concentration, and ground with a Wiley mill (1-mm screen; Arthur H. Thomas Co., Philadelphia, PA). Feed ingredients collected during the TP were analyzed by week, whereas feed ingredients from the $\mathrm{CO}$ period were composited every $2 \mathrm{wk}$ for forages and every $4 \mathrm{wk}$ for concentrates before drying. All feed ingredients and composites were analyzed for DM, ash, NDF, CP, and starch, and samples collected during the TP were also analyzed for gross energy concentration. All nutrients are expressed as percentages of $\mathrm{DM}$, determined by drying at $105^{\circ} \mathrm{C}$ in a forced-air oven for more than $8 \mathrm{~h}$ (Table 2). Ash concentration was determined after $5 \mathrm{~h}$ of oxidation at $500^{\circ} \mathrm{C}$ in a muffle furnace. Concentration of NDF was determined according to Mertens (2002) and CP was determined according to Hach et al. (1987). Gross energy in samples collected during the TP was determined by bomb calorimetry according to the manufacturer's instructions (Parr Instrument Inc., Moline, IL). Starch in samples was measured by gelatinization with sodium hydroxide and subsequent hydrolysis to glucose using an enzymatic method (Karkalas, 1985). Glucose was then measured with a glucose oxidase method (PGO Enzyme Product No. P7119, Sigma Chemical Co., St. Louis, MO) and by determination of absorbance with a microplate reader (SpectraMax 190, Molecular Devices Corp., Sunnyvale, CA). Milk samples were analyzed for fat, true protein, lactose, MUN concentration, and SCC by mid-infrared spectroscopy (AOAC International, 1997) by the Michigan Herd Improvement Association (Universal Lab Services). Components corrected milk yields were calculated using the following formulas:

$$
\begin{gathered}
3.5 \% \text { FCM }(\mathrm{kg} / \mathrm{d})=0.4324 \times \text { milk }(\mathrm{kg} / \mathrm{d}) \\
+16.216 \times \text { fat }(\mathrm{kg} / \mathrm{d})
\end{gathered}
$$

$\operatorname{ECM}(\mathrm{kg} / \mathrm{d})=0.327 \times$ milk $(\mathrm{kg} / \mathrm{d}) 12.95$ fat $(\mathrm{kg} / \mathrm{d})$

$$
+7.65 \times \text { protein }(\mathrm{kg} / \mathrm{d}) \text {. }
$$

Total yield of 3.5\% FCM, ECM, and milk components for each sampling day were calculated by summing milk yield and component concentrations from each milking.

Blood plasma samples were analyzed with commercial kits for glucose using a glucose oxidase method (PGO Enzyme Product No. P7119; Sigma Chemical Co.; intraassay CV: $1.61 \%$, interassay CV: $1.00 \%$ ), insulin (Bovine insulin ELISA, \#10-1201-01, Mercodia, Uppsala, Sweden; intraassay CV: $5.78 \%$, interassay CV: $8.27 \%$ ) and nonesterified fatty acids [NEFA; NEFAHR(2) kit; Wako Chemicals USA Inc., Richmond, VA; intraassay CV: $2.39 \%$, interassay CV: 2.81\%]. Plasma samples collected prepartum and during the TP were analyzed for concentrations of glucagon (Glucagon RIA kit no. GL-32K, 77 Millipore Corp., St. Charles, MO; Hammon and Blum, 1998; intraassay CV: 5.30\%), BHB (kit no. 2240, Stanbio Laboratory, Boerne, TX; intraassay CV: $3.18 \%$, interassay CV: $4.46 \%$ ), triglycerides (L-Type Triglyceride M kit, Wako Chemicals USA; intraassay CV: $2.23 \%$, interassay CV: $3.81 \%$ ), and lactate (YSI 1500 Sport Lactate Analyzer, Yellow Springs Instrument Co., Yellow Springs, OH; intraassay CV: $3.27 \%)$.

\section{Statistical Analysis}

Data were analyzed separately for the TP (from 1 to $23 \mathrm{~d} \mathrm{PP}$ ) and for the CO period (from 24 to $72 \mathrm{~d} \mathrm{PP}$ ) as required to evaluate treatment effects during early $\mathrm{PP}$ and its residual effects. All data were analyzed using the Fit Model procedure of JMP Pro (version 13, SAS Institute Inc., Cary, NC) according to the following model:

$$
\begin{gathered}
\mathrm{Y}_{\mathrm{ijosf}}=\mu+\mathrm{B}_{\mathrm{i}}+\mathrm{C}\left(\mathrm{B}_{\mathrm{i}}\right)_{\mathrm{j}}+\mathrm{J}+\mathrm{O}_{\mathrm{o}}+\mathrm{S}_{\mathrm{s}}+\mathrm{F}_{\mathrm{f}}+\mathrm{S}_{\mathrm{s}} \mathrm{F}_{\mathrm{f}} \\
+\mathrm{T}+\mathrm{S}_{\mathrm{s}} \mathrm{T}+\mathrm{F}_{\mathrm{f}} \mathrm{T}+\mathrm{S}_{\mathrm{s}} \mathrm{F}_{\mathrm{f}} \mathrm{T}+\mathrm{COV}+\mathrm{e}_{\mathrm{ijosf}},
\end{gathered}
$$

where $\mathrm{Y}_{\mathrm{ijosf}}=$ response variable; $\mu=$ overall mean; $\mathrm{B}_{\mathrm{i}}=$ random effect of block ( $\mathrm{i}=1$ to 13$) ; \mathrm{C}\left(\mathrm{B}_{\mathrm{i}}\right)_{\mathrm{j}}=$ random effect of cow ( $\mathrm{j}=1$ to 4 ) within block; $\mathrm{J}=$ random effect of Julian date; $\mathrm{O}_{\mathrm{o}}=$ day offset from fixed weekly sampling day $(\mathrm{o}=-3$ to +3$) ; \mathrm{S}_{\mathrm{s}}=$ fixed effect of $\mathrm{SC}$ ( $\mathrm{s}=1$ to 2$) ; \mathrm{F}_{\mathrm{f}}=$ fixed effect of $\mathrm{SF}(\mathrm{f}=1$ to 2$) ; \mathrm{S}_{\mathrm{s}} \mathrm{F}_{\mathrm{f}}$ $=$ interaction between $\mathrm{SC}$ and $\mathrm{SF} ; \mathrm{T}=$ fixed effect of sampling day $\mathrm{PP} ; \mathrm{S}_{\mathrm{s}} \mathrm{T}=$ interaction between $\mathrm{SC}$ and day PP; $\mathrm{F}_{\mathrm{f}} \mathrm{T}=$ interaction between $\mathrm{SF}$ and day PP; $\mathrm{S}_{\mathrm{s}} \mathrm{F}_{\mathrm{f}} \mathrm{T}=$ interaction between $\mathrm{SC}, \mathrm{SF}$, and day PP; COV $=$ covariate variable corresponding to the response variable; and $\mathrm{e}_{\mathrm{ijosf}}=$ residual error. 
Measurements determined prepartum and at calving (BCS and BW) were included in the model as covariates except for DMI. Day PP was included in the model as a continuous measure, and therefore standard errors of the means are not reported for figures. Linear and quadratic interactions between main effects and sampling day $\mathrm{PP}$ were evaluated for $\mathrm{TP}$ and $\mathrm{CO}$ periods, but removed from the model for the analysis of cumulative DMI and milk yield, and change in BCS, BW, and BFT for each period. Also, interactions with time were removed from the model when nonsignificant and a reduced model was used to determine treatment effects. However, all interactions were included in the tables for informational purposes. Normality of the residuals was checked with normal probability and box plots and homogeneity of variances with plots of residuals versus predicted values. Goodness of normal fit was also tested with Shapiro-Wilk test, and variables were transformed when necessary to fit a normal distribution. Data from the last 4 wk of the $\mathrm{CO}$ period from a cow receiving the HS-DGC treatment were removed because of abnormal recovery from an udder infection from eczema. Treatment effects were declared significant at $P<0.05$ and tendencies at $P<0.10$. Interactions were declared significant at $P<0.10$ and tendencies at $P<0.15$.

\section{RESULTS}

\section{Treatment Period}

DMI and Production Response. Although DMI and milk yield were collected daily, values in Table 3 are from collection days to correspond with milk components data. Dry matter intake increased over time for both starch sources, but DGC increased DMI compared with HMC throughout the TP $(P=0.12$, linear; Table 3). Data for daily DMI are represented in Figure 1A. Over the TP, HMC decreased DMI compared with DGC to a greater extent when included in the HS (3.9 $\mathrm{kg} / \mathrm{d})$ than the LS $(0.9 \mathrm{~kg} / \mathrm{d})$ diets $(P=0.07)$. The HMC treatment decreased cumulative DMI by 52.9 $\mathrm{kg}$ compared with DGC during the TP $(P<0.01)$, whereas no effect of SC was observed. Similarly, HMC decreased milk yield by $4.3 \mathrm{~kg} / \mathrm{d}(P=0.02)$ and cumulative milk yield by $60.2 \mathrm{~kg}(P=0.08)$ over the TP. Starch fermentability treatments interacted over time for milk yield with HMC decreasing milk yield more compared with DGC as time progressed $(P=0.09$, quadratic). Data for daily milk yield are represented in Figure 1B. The HMC treatment also decreased yields of milk fat, protein, and lactose by $0.19(P=0.03), 0.18$ $(P=0.01)$, and $0.19(P=0.05) \mathrm{kg} / \mathrm{d}$ compared with DGC, respectively (Table 3). Milk fat yield increased over time for DGC but decreased for HMC $(P<0.01$, linear; Figure 2A), whereas the difference in protein yield between starch sources was greater during the second week of the TP $(P=0.03$, quadratic; Figure 2B). Correspondingly, HMC decreased yields of FCM and ECM by $4.8(P=0.02)$ and $5.0(P=0.01) \mathrm{kg} / \mathrm{d}$ when compared with DGC, respectively, with both FCM and ECM linearly increasing throughout the TP for DGC and decreasing for HMC treatments $(P=0.01$, Figure $2 \mathrm{C}$, and $P=0.01$, linear, respectively).

Concentrations of fat and lactose in milk were not affected by treatments during the TP, although fat concentration tended to decrease over time for all the treatments, but more for HS-HMC after the first week PP $(P$ $=0.14$, linear), and lactose concentration increased over time for all the treatments, but more for LS-HMC after the first week PP $(P=0.03$, linear; Table 3$)$. However, HS-DGC increased milk protein concentration the most $(3.21 \%)$ and HS-HMC decreased it the most $(2.97 \%)$ with similar concentrations observed for both LS-DGC $(3.08 \%)$ and LS-HMC (3.09\%) treatments (interaction, $P=0.10)$. Treatments did not affect concentration of MUN and SCC, although HS tended to increase SCC and LS tended to decrease SCC throughout the TP $(P$ $=0.13$, linear $)$.

Body Reserves. The HMC treatment decreased BW compared with DGC $(P=0.01)$ and reduction was greater for HS (683 vs. $719 \mathrm{~kg}$ ) compared with LS diets $(699$ vs. $703 \mathrm{~kg}$, interaction, $P=0.05$; Table 4). Whereas BW decreased for all treatments throughout the TP, HS-HMC decreased BW more during the second week PP compared with the other treatments $(P<0.01$, quadratic $)$. Treatments interacted to affect change in BCS with HMC increasing loss in BCS ( -0.38 vs. -0.17 units) compared with DGC in HS diets and decreasing loss in BCS ( -0.21 vs. -0.29 units) compared with DGC in LS diets (interaction, $P$ $=0.09$ ). Treatments also interacted to affect BFT with HMC increasing BFT (0.49 vs. $0.46 \mathrm{~cm}$ ) compared with DGC in HS diets and decreasing BFT (0.45 vs. 0.54 $\mathrm{cm}$ ) compared with DGC in LS diets (interaction, $P=$ 0.11 ). Treatments did not affect BCS or the change in BW or BFT measured throughout the TP.

Plasma Metabolites and Hormones. The HS treatments increased glucose $(P=0.06$, linear; Table 4 ) and tended to increase insulin $(P=0.13$, linear $)$ concentrations over time compared with LS for most of the TP, but concentrations were similar among treatments by the third week PP and no main treatment effect over the TP was detected. Over time, plasma NEFA concentration decreased for all treatments, but HS-HMC increased plasma NEFA concentration more during the first week PP compared with the rest of the 
DIET STARCH FERMENTABILITY FOR FRESH COWS

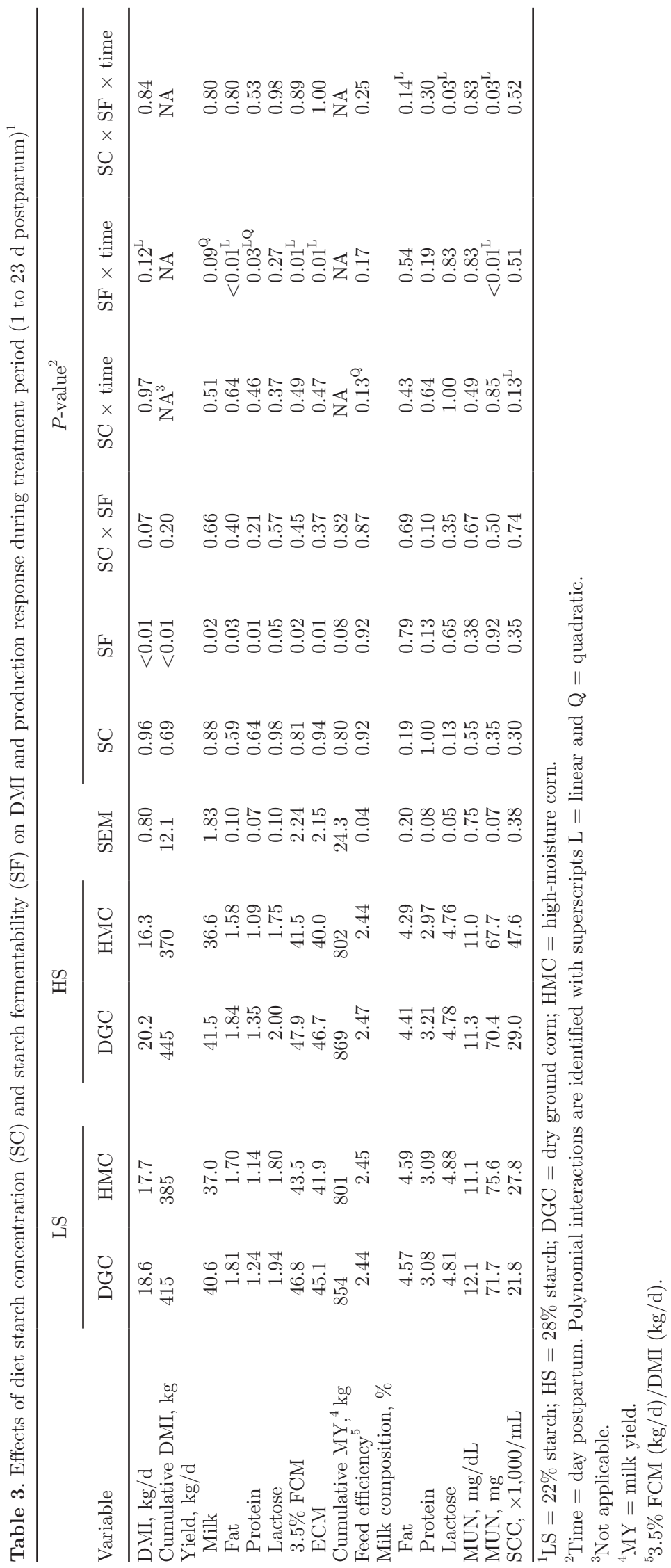


treatments, with this effect diminished by the second week PP $(P=0.05$, quadratic) with no main effects of treatments detected.

The DGC treatment increased concentrations of plasma glucagon and BHB compared with HMC in HS diets (138 vs. $125 \mathrm{pg} / \mathrm{mL}$ and 11.8 vs. $7.24 \mathrm{mg} /$ $\mathrm{dL}$, respectively) but decreased their concentrations compared with HMC in LS diets (131 vs. $141 \mathrm{pg} /$ $\mathrm{mL}$ and 9.63 vs. $14.8 \mathrm{mg} / \mathrm{dL}$; interactions, $P=0.06$ and $P=0.01$, respectively; Table 4 ). In both cases, LS-HMC and HS-DGC increased, and HS-HMC and LS-DGC decreased plasma glucagon and BHB concentrations after the first week $\mathrm{PP}(P=0.01$ and $P=0.03$,
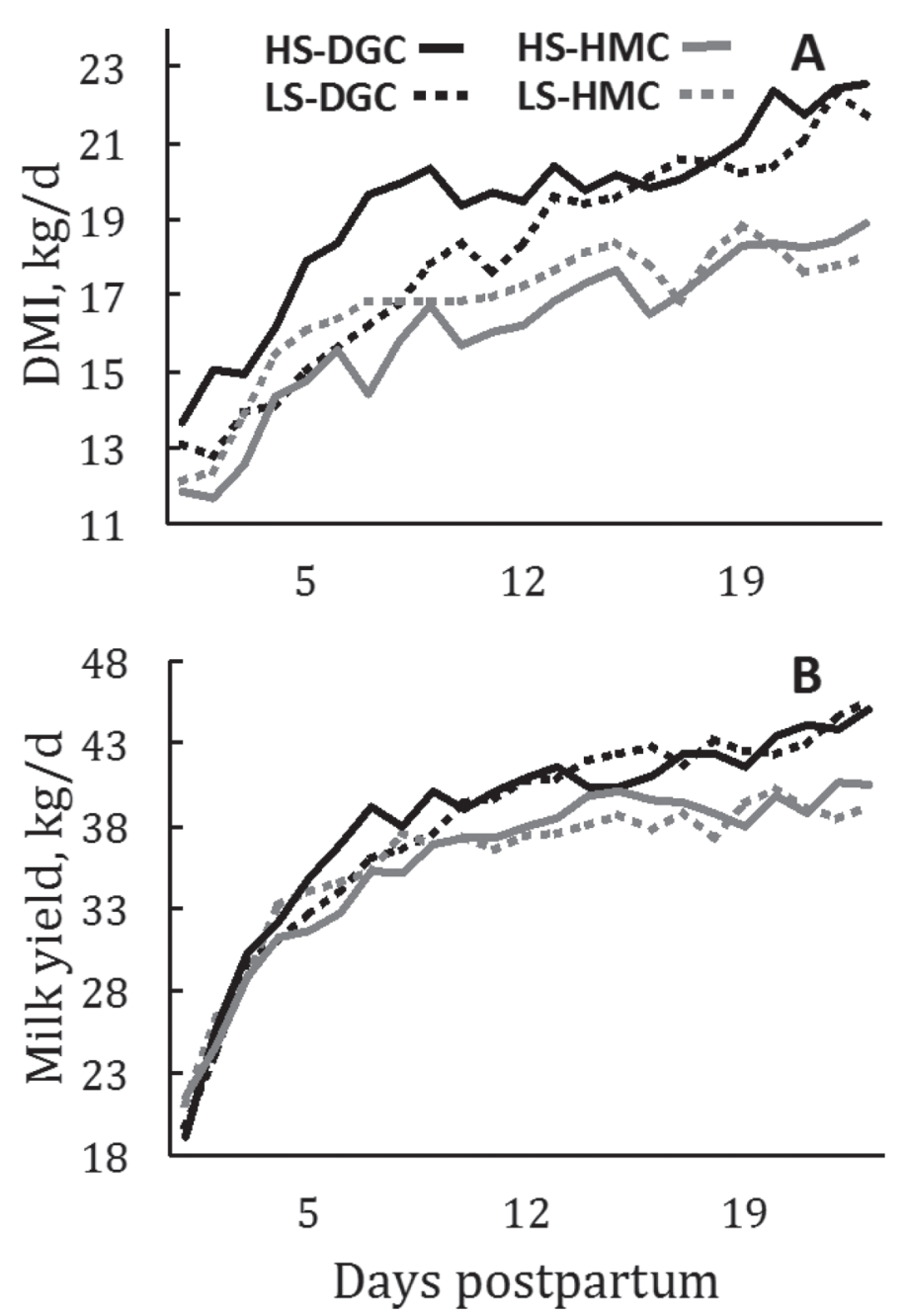

Figure 1. Effects of diet starch concentration (SC) and fermentability (SF) on daily (A) DMI and (B) milk yield during treatment period (1 to 23 d postpartum). Treatments are represented as $28 \%$ starch with dry ground corn (HS-DGC; black, solid line), $22 \%$ starch with dry ground corn (LS-DGC; black, broken line), $28 \%$ starch with high-moisture corn (HS-HMC; gray, solid line), and $22 \%$ starch with high-moisture corn (LS-HMC; gray, broken line). Interactions among $\mathrm{SC}, \mathrm{SF}$, and day postpartum were significant for DMI $(P<0.01$, linear and $P=0.12$, quadratic $)$ and milk yield $(P<0.01$, linear $)$. quadratic, respectively), with all treatments reaching similar glucagon concentrations by the third week PP. However, BHB concentrations were greater for LSHMC and HS-DGC throughout the TP. Opposite to
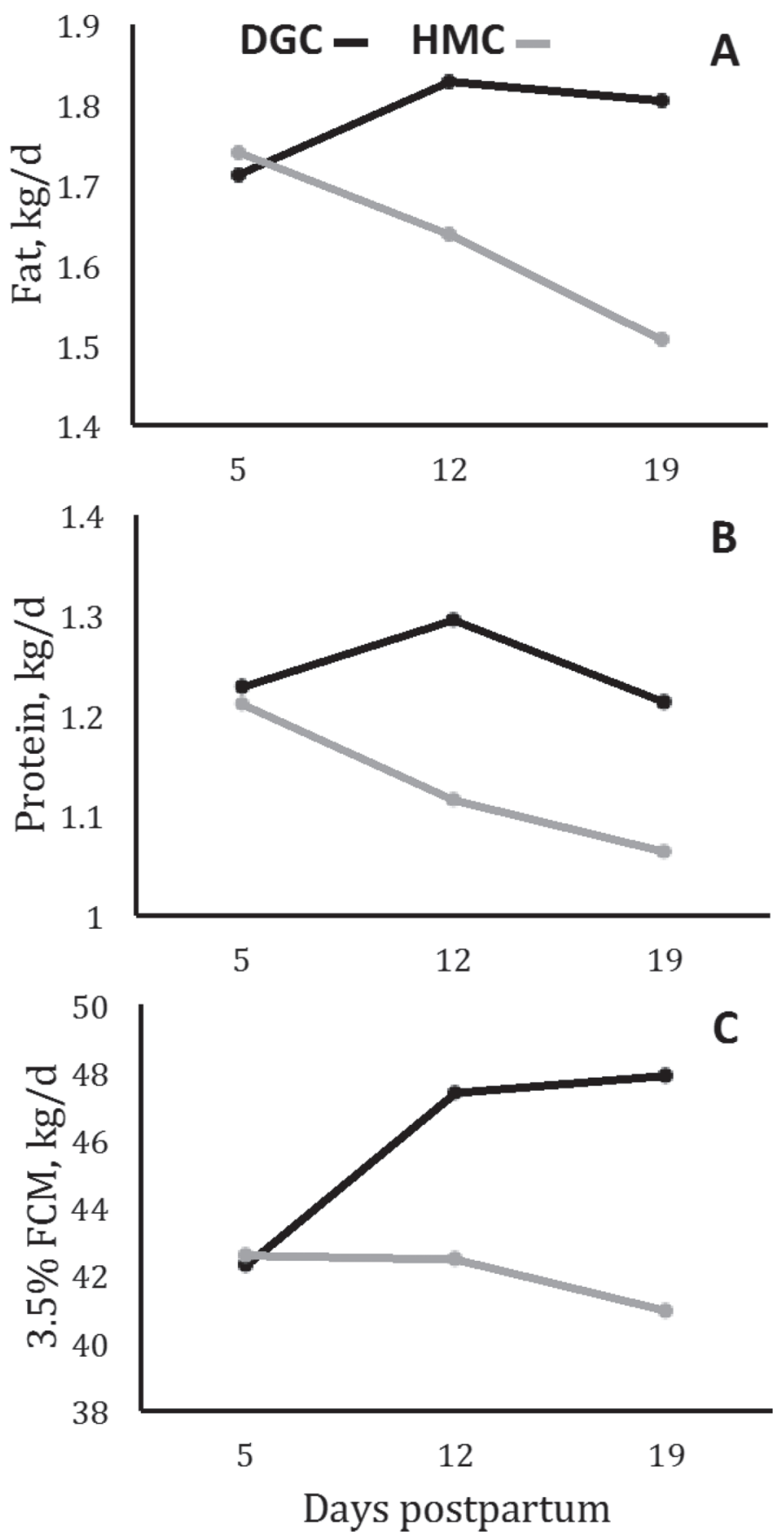

Figure 2. Effects of diet starch fermentability (SF) on (A) milk fat yield, (B) milk protein yield, and (C) $3.5 \%$ FCM yield during treatment period (1 to $23 \mathrm{~d}$ postpartum). Treatments are represented as dry ground corn (DGC; black line) and high-moisture corn (HMC; gray line). Interaction between $\mathrm{SF}$ and day postpartum was significant for yields of milk fat $(P<0.01$, linear $)$, protein $(P=0.10$, linear and $P$ $=0.03$, quadratic $)$, and $3.5 \%$ FCM $(P=0.01$, linear; Table 3$)$. 
DIET STARCH FERMENTABILITY FOR FRESH COWS

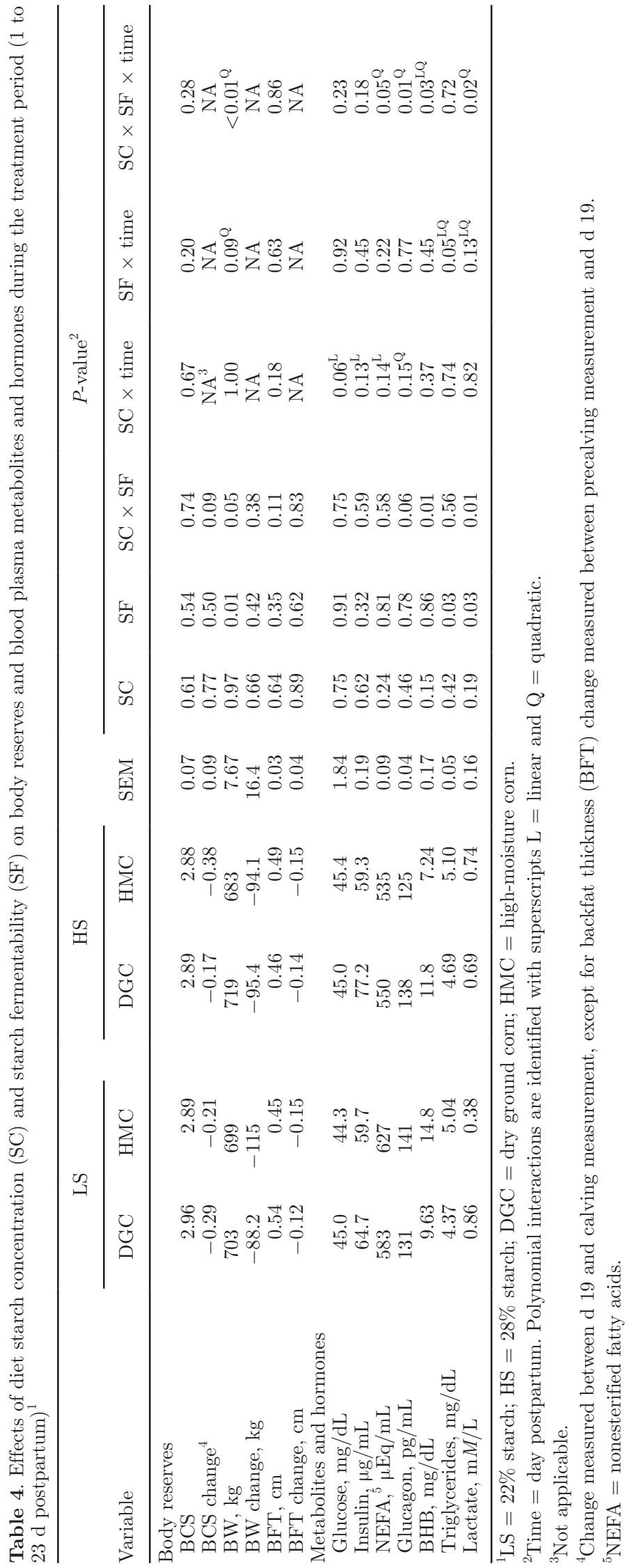


these effects, HMC increased plasma lactate concentration compared with DGC in HS diets (0.74 vs. 0.69 $\mathrm{m} M / \mathrm{dL}$ ), but decreased plasma lactate concentration compared with DGC in LS diets (0.38 vs. $0.86 \mathrm{mM}$ / $\mathrm{dL}$, respectively; interaction, $P=0.01$; Table 4). After the first week PP, both HMC treatments and HS-DGC decreased, whereas LS-DGC increased plasma lactate concentration by wk 2 , with all treatments reaching similar concentration values by the third week PP $(P=$ 0.02 , quadratic). The HMC treatment increased plasma triglyceride concentration compared with DGC (5.07 vs. $4.53 \mathrm{mg} / \mathrm{dL}$, respectively; interaction, $P=0.01$; Table 4). Plasma triglyceride concentration was affected by SF only; HMC increased plasma triglyceride concentration compared with DGC (5.07 vs. $4.53 \mathrm{mg} / \mathrm{dL}, P=$ $0.03)$ after the first week PP $(P=0.05$, quadratic $)$.

\section{Carryover Period}

DMI and Production Response. Treatment effects on DMI observed during the TP diminished during the $\mathrm{CO}$ period when a common diet was fed (Table 5) with a greater DMI for the DGC treatments during the first 2 wk of the $\mathrm{CO}$ period and little difference among treatments after that $(P=0.06$, quadratic $)$. No effects of treatment were observed for cumulative DMI and cumulative milk yield throughout the $\mathrm{CO}$ period. However, interactions between $\mathrm{SC}$ and $\mathrm{SF}$ were detected with DGC compared with HMC increasing milk yield ( 54.8 vs. $51.0 \mathrm{~kg} / \mathrm{d}$, tendency, $P=0.12$ ), milk fat yield $(1.76$ vs. $1.64 \mathrm{~kg} / \mathrm{d}, P=0.08), 3.5 \% \mathrm{FCM}$ (51.3 vs. 48.6 $\mathrm{kg} / \mathrm{d}, P=0.06)$, ECM (50.0 vs. $47.5 \mathrm{~kg} / \mathrm{d}, P=0.09)$, and feed efficiency (2.01 vs. 1.91, $P=0.08$ ) for HS and decreasing milk yield ( 51.2 vs. $52.8 \mathrm{~kg} / \mathrm{d})$, milk fat yield (1.68 vs. $1.81 \mathrm{~kg} / \mathrm{d}), 3.5 \%$ FCM (48.4 vs. $52.2 \mathrm{~kg} / \mathrm{d}$ ), ECM (47.4 vs. $50.6 \mathrm{~kg} / \mathrm{d}$ ), and feed efficiency (1.89 vs. 2.04) for LS (Table 5). Treatments interacted with time to affect yield of milk protein and lactose, but no main effects of treatment or their interaction were detected.

Treatments interacted with time to affect milk fat concentration $(P=0.02$, linear $)$ with a greater reduction over time for LS-HMC compared with the other treatments, but no main effects of treatment or their interaction were detected. Treatments tended to interact with time to affect milk protein concentration with HSDGC decreasing and the other treatments increasing protein concentration over time $(P=0.12$, quadratic), but no main effects of treatment or their interaction were detected. The HMC treatment tended to increase milk lactose concentration compared with DGC (4.98 vs. $4.92 \%$, respectively, $P=0.09)$. The HMC treatment tended to increase MUN concentration over time compared with DGC $(P=0.12$, linear $)$ but no effect of $\mathrm{SF}$ was detected. There were no overall effects of treat- ment on SCC during the CO period. However, the DGC treatments increased SCC throughout the $\mathrm{CO}$ period, whereas the HMC treatments had opposite effects for LS and HS diets with a slight increase in SCC until wk 7 followed by a slight reduction with the LS diet and a large reduction until wk 7 followed by a large increase with the HS diet ( $P=0.08$, quadratic).

Body Reserves. Treatments tended to interact over time with HS-DGC decreasing and all other treatments increasing BW over time $(P=0.12$, linear; Table 6$)$. The reduction in BW for the HS-DGC treatment resulted in a treatment effect for BW change during the $\mathrm{CO}$ period with HS decreasing BW compared with LS $(-5.7$ vs. $7.0 \mathrm{~kg}, P=0.01)$, although no interaction of main effects were detected. Body condition score decreased for all treatments throughout the $\mathrm{CO}$ period, but the decrease was less over the first few weeks and more over the remaining weeks for HS-HMC compared with the other treatments $(P=0.04$, quadratic) and no overall effects of treatment for BCS or change in BCS were observed. Backfat thickness decreased during the $\mathrm{CO}$ period for all treatments, but HMC tended to increase BFT compared with DGC (0.30 vs. $0.21 \mathrm{~cm}$, $P=0.06)$ and interactions over time were detected for SF $(P=0.07$, quadratic $)$ and $\mathrm{SC}(P=0.08$, linear $)$. A tendency for an interaction between SF and SC for change in BFT was detected $(P=0.11)$ with a greater reduction by DGC compared with HMC for HS $(-0.20$ vs. $-0.12 \mathrm{~cm})$ and a greater reduction by $\mathrm{HMC}$ compared with DGC for LS ( -0.15 vs. $-0.10 \mathrm{~cm})$.

Plasma Metabolites and Hormones. No effects of treatment were detected for plasma glucose concentration (Table 6). The HMC treatment increased plasma insulin concentration more over time compared with DGC $(P=0.05$, linear), but plasma insulin concentration was lower for the first 2 wk of the CO period and no main effects of treatment or their interaction were detected. Treatments tended to interact to affect plasma NEFA concentration with DGC increasing NEFA compared with HMC in HS diets (277 vs. 248 $\mu \mathrm{Eq} / \mathrm{mL}$ ) and DGC decreasing NEFA compared with HMC in LS diets (218 vs. $252 \mu \mathrm{Eq} / \mathrm{mL} ; P=0.11$; Table $6)$.

\section{DISCUSSION}

\section{Treatment Effects During the Treatment Period}

The reduction in DMI by the more fermentable HMC treatment compared with DGC and the greater reduction when fed at higher SC was in agreement with our hypothesis. The lack of overall effect of SC on DMI is in contrast to results reported previously by Rabelo et al. (2003) and Andersen et al. (2003). However, in those 
DIET STARCH FERMENTABILITY FOR FRESH COWS

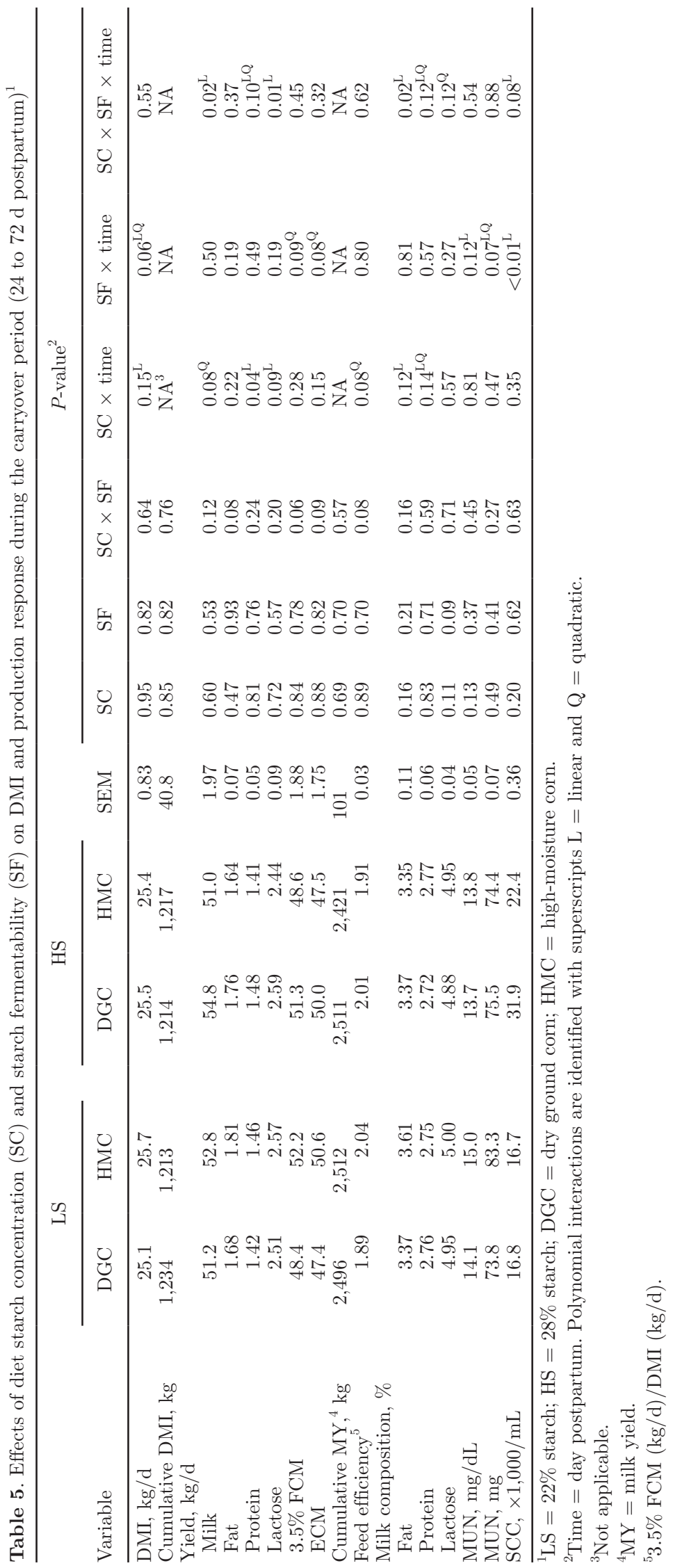




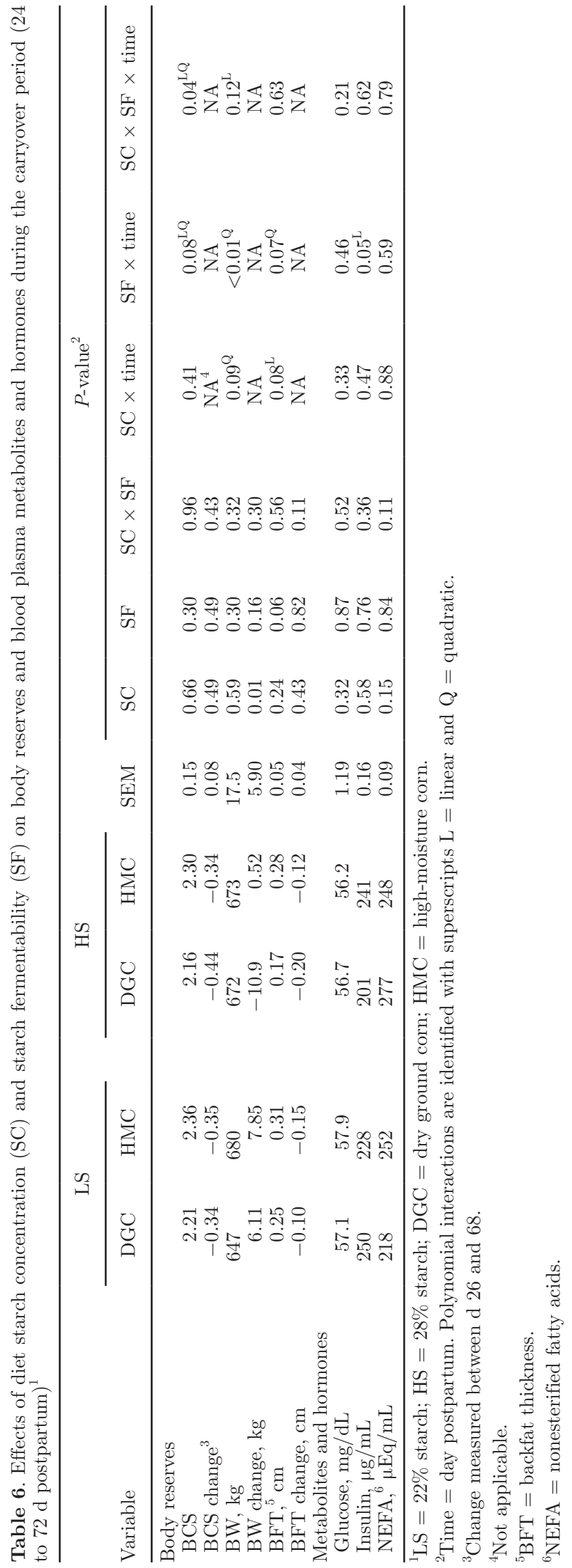

experiments grains were substituted for forage, decreasing the fNDF concentration of the diet. Forage NDF is very filling (Allen, 2000) and greater fNDF concentration of the lower starch diets might have contributed to satiety by increasing ruminal distention, especially as lactation progressed and the lipolytic state diminished. Nonforage NDF is much less filling than fNDF (Allen, 2000) and increasing diet starch concentration from $\sim 21$ to $\sim 26 \%$ by replacing nonforage NDF sources with starch sources with moderate ruminal fermentability during the first $21 \mathrm{~d}$ PP did not affect DMI in studies reported by Nelson et al. (2011) and McCarthy et al. (2015a), likely because increasing diet starch concentration did not reduce the filling effect of diets.

Hypophagic effects of diets with highly fermentable starch compared with less fermentable starch (HMC vs. DGC, respectively) have been reported for cows past peak lactation (Oba and Allen, 2003a; Bradford and Allen, 2007). In addition, Sadri et al. (2009) reported that increasing diet starch fermentability by substituting dry ground barley for DGC decreased DMI 1.4 $\mathrm{kg} / \mathrm{d}$ during the first $28 \mathrm{~d}$ PP despite a greater NFC concentration for the DGC diet (40.6\%) compared with the ground barley diet (38\%). Depression in feed intake by highly fermentable starch sources likely occurs because of greater ruminal propionate flux to the liver, which stimulates hepatic oxidation and generation of ATP, reducing meal size (Allen, 2014). Propionate is an obligate anaplerotic metabolite and must enter the tricarboxylic acid (TCA) cycle before contributing to gluconeogenesis (Gualdrón-Duarte and Allen, 2017). Anaplerosis of the TCA by propionate stimulates oxidation of acetyl CoA, causing satiety (Allen and Piantoni, 2013; Allen, 2014). In contrast, when site of starch digestion is shifted postruminally, a positive response in feed intake is expected. This is because the fuels absorbed do not stimulate hepatic oxidation to the same degree as propionate and because of increased latency for fuels reaching the liver; transit time from the rumen to the intestines significantly delays fuel absorption. Starch escaping the rumen is digested to glucose, which is absorbed and partially metabolized to lactate. Because liver uptake of lactate is much lower than propionate (Reynolds et al., 2003), lactate is expected to have less effect on satiety than propionate. Abomasal infusion of propionic acid decreased total ME intake (diet plus infusion) compared with control (no infusion) from 40.1 to $34.8 \mathrm{Mcal} / \mathrm{d}$ but iso-energetic abomasal infusions of glucose and lactic acid did not decrease ME intake compared with control (GualdrónDuarte and Allen, 2018).

Dann et al. (1999) reported that increasing diet starch fermentability by substituting steam-rolled corn for cracked corn from 1 to $63 \mathrm{~d}$ PP tended to reduce 
DMI $(P=0.13)$. It is likely that control of feed intake by hepatic oxidation diminishes as the lipolytic state subsides and distention begins to limit feed intake as lactation progresses (Allen and Piantoni, 2013). It is not known if the effects of treatment on DMI in the study reported by Dann et al. (1999) were greater during the PP period because treatment by time interaction was not reported.

Increasing ruminal starch digestibility by substituting HMC for DGC did not affect DMI in the study reported by Rockwell and Allen (2016). However, DMI normally increases steadily during the PP period, but in that study DMI plateaued at $\sim 10 \mathrm{~d}$ PP, likely because DMI began to be limited by distention from the highly filling diets containing $27.4 \%$ forage NDF rather than being controlled by metabolic effects associated with starch fermentability. In evidence of this, DMI increased rapidly when a common diet with lower forage NDF concentration was offered during the carryover period.

Oba and Allen (2003b) reported that propionate was more hypophagic for cows in the early PP period compared with mid-lactation. Cows in negative energy balance during the early PP period are in a lipolytic state and $\beta$-oxidation of NEFA in the mitochondria results in an abundant supply of acetyl CoA for oxidation in the TCA cycle. Increased starch fermentability by the HMC treatments in our study likely increased ruminal production of propionic acid and supply of propionate to the liver, stimulating oxidation of acetyl CoA and depressing DMI, and to a greater extent when the inclusion of HMC in the diet was increased with greater starch concentration.

Effects of SF treatment on yields of milk, FCM, ECM, and milk components were similar to effects on DMI with HMC decreasing yields over time compared with DGC. However, unlike DMI, the effects were independent of diet SC. Concentrations of milk components (except protein) and feed efficiency were not affected, suggesting that the negative effects of HMC on production was from its effects on DMI, possibly partially compensated by the increase in mobilization of body reserves for the HS-HMC treatment that had a greater loss in BCS (but not BW or BFT) compared with the other treatments. Also, the reduction in milk fat yield by HMC, without differences in milk fat concentration between treatments, suggests that depression in DMI and milk yield caused this effect rather than factors associated with milk fat depression.

In contrast to our results, increasing SC of diets fed during the first $21 \mathrm{~d}$ PP from 21.5 to $26.2 \%$ increased plasma glucose and insulin concentrations and reduced plasma NEFA and BHB concentrations in the study reported by McCarthy et al. (2015b). Whereas HS in- creased plasma glucose and insulin concentrations compared with LS through most of the treatment period, main effects of treatment for glucose, insulin, and NEFA were not detected in our study. In our study, treatments interacted to affect plasma BHB concentrations with HS increasing BHB concentration for DGC compared with HMC, and LS increasing BHB concentration for HMC compared with DGC.

Sadri et al. (2012) reported that a more fermentable starch source (dry ground barley vs. DGC) increased plasma glucagon concentration, which is consistent with our results for the LS diet but not the HS diet for which the reverse occurred. Although they did not report the starch concentration of the treatment diets, the NDF concentration was similar to the NDF concentration of our LS diets at 32 to $34 \%$.

\section{Carryover Effects of Treatment Diets}

Treatment effects on DMI, milk yield, and milk components during the TP diminished during the $\mathrm{CO}$ period when a common diet was offered. However, LSHMC and HS-DGC increased yields of daily milk, fat, FCM, and ECM throughout the CO period, increasing feed efficiency. In addition, HS-DGC increased yields of protein and lactose more than other treatments for most of the CO period. The lack of a carryover effect for the LS-DGC treatment and the increased effect on production for the LS-HMC indicate a possible programming effect of treatments during the PP period. Whereas the effect of HS-DGC on yields of milk and milk components during the TP persisted through the $\mathrm{CO}$ period, a priming effect apparently occurred for LS-HMC during TP that improved production during the CO period. Switching from TP diets to a common diet with reduced filling effect (lower fNDF) and higher starch concentration, coupled with a slight increase in mobilization of body reserves during the $\mathrm{CO}$ period, particularly for HS-DGC, may have influenced these effects. Of interest is the relationship between increased BHB concentration during TP for both LS-HMC and HS-DGC and their positive association with production during the $\mathrm{CO}$ period. Similar relationships between plasma BHB during the early PP period and positive carryover effects on production exist in previous studies from cows receiving either nonsteroidal anti-inflammatory drugs (Farney et al., 2013a,b; Carpenter et al., 2016) or dietary treatments (Piantoni et al., 2015b; de Souza, 2018) within the first 4 wk PP. It is important to note that these effects were not consistent with DMI, production, or blood concentration of hormones and metabolites, other than BHB, during the treatment period. To our knowledge, mechanisms involved in increasing circulating levels of BHB during the early 
$\mathrm{PP}$ period and its relationship with positive carryover effects on production have not been investigated.

\section{CONCLUSIONS}

Feeding HMC, a highly fermentable starch source, decreased DMI and yields of milk and milk components during the early PP period consistent with the hepatic oxidation theory of control of feed intake (Allen et al., 2009). Negative effects of HMC compared with DGC on DMI were increased when diet starch concentration increased, but starch concentration had no main effects on yield of milk or milk components. Despite the lack of difference in DMI among treatments, yields of milk, fat, FCM, and ECM were increased by LS-HMC and HS-DGC during the CO period. Reasons for this effect are uncertain, but it is possible that treatment effects during the early PP period may have programming effects on production later in lactation. A potential relationship with blood $\mathrm{BHB}$ concentrations during $\mathrm{TP}$ may have influenced this effect, but further research is needed to elucidate the mechanisms involved.

\section{ACKNOWLEDGMENTS}

We acknowledge financial support for this project by USDA National Research Initiative Competitive Grant no. 2014-67015-21708 to MSA, as well as funding from the Fulbright Argentina Program and the Office for International Students and Scholars at Michigan State University to RIA. We also thank D. G. Main, R. Longuski, K. Kennedy, L. Gualdron-Duarte, G. Maldini, R. Yair, and R. West (all from Michigan State University), as well as the staff from the Michigan State University Dairy Cattle Teaching and Research Center (East Lansing) for their assistance with this experiment.

\section{REFERENCES}

Allen, M. S. 2000. Effects of diet on short-term regulation of feed intake by lactating dairy cattle. J. Dairy Sci. 83:1598-1624.

Allen, M. S. 2014. Drives and limits to feed intake in ruminants. Anim. Prod. Sci. 54:1513-1524.

Allen, M. S., B. Bradford, and M. Oba. 2009. Board-invited review: The hepatic oxidation theory of the control of feed intake and its application to ruminants. J. Anim. Sci. 87:3317-3334.

Allen, M. S., and P. Piantoni. 2013. Metabolic control of feed intake: Implications for metabolic disease of fresh cows. Vet. Clin. North Am. Food Anim. Pract. 29:279-297.

Andersen, J. B., N. C. Friggens, K. Sejrsen, M. T. Sørensen, L. Munksgaard, and K. L. Ingvartsen. 2003. The effects of low vs. high concentrate level in the diet on performance in cows milked two or three times daily in early lactation. Livest. Prod. Sci. 81:119-128.

AOAC International. 1997. Official Methods of Analysis. 16th ed. AOAC International, Gaithersburg, MD.

Bradford, B. J., and M. S. Allen. 2007. Depression in feed intake by a highly fermentable diet is related to plasma insulin concentration and insulin response to glucose infusion. J. Dairy Sci. 90:38383845
Butler, W. R. 2003. Energy balance relationships with follicular development, ovulation and fertility in postpartum dairy cows. Livest. Prod. Sci. 83:211-218.

Carpenter, A. J., C. M. Ylioja, C. F. Vargas, L. K. Mamedova, L. G. Mendonça, J. F. Coetzee, L. C. Hollis, R. Gehring, and B. J. Bradford. 2016. Hot topic: Early postpartum treatment of commercial dairy cows with nonsteroidal antiinflammatory drugs increases whole-lactation milk yield. J. Dairy Sci. 99:672-679.

Dann, H. M., G. A. Varga, and D. E. Putnam. 1999. Improving energy supply to late gestation and early postpartum dairy cows. J. Dairy Sci. 82:1765-1778.

de Souza, J. 2018. Changing the dietary ratio of fatty acids under different physiological conditions alters energy partitioning of dairy cows. PhD dissertation. Michigan State University, East Lansing.

Farney, J. K., L. K. Mamedova, J. F. Coetzee, B. KuKanich, L. M. Sordillo, S. K. Stoakes, J. E. Minton, L. C. Hollis, and B. J. Bradford. 2013a. Anti-inflammatory salicylate treatment alters the metabolic adaptations to lactation in dairy cattle. Am. J. Physiol. Regul. Integr. Comp. Physiol. 305:R110-R117.

Farney, J. K., L. K. Mamedova, J. F. Coetzee, J. E. Minton, L. C. Hollis, and B. J. Bradford. 2013b. Sodium salicylate treatment in early lactation increases whole-lactation milk and milk fat yield in mature dairy cows. J. Dairy Sci. 96:7709-7718.

Goering, H. K., and P. J. Van Soest. 1970. Forage Fiber Analysis (Apparatus, Reagents, Procedures, and Some Applications). Agricultural Handbook no. 379. Agricultural Research Service-USDA, Washington, DC

Gualdrón-Duarte, L. B., and M. S. Allen. 2017. Increased anaplerosis of the tricarboxylic acid cycle decreased meal size and energy intake of cows in the postpartum period. J. Dairy Sci. 100:4425-4434.

Gualdrón-Duarte, L. B., and M. S. Allen. 2018. Fuels derived from starch digestion have different effects on energy intake and metabolic responses of cows in the postpartum period. J. Dairy Sci 101:5082-5091. https://doi.org/10.3168/jds.2017-13607.

Hach, C. C., B. K. Bowden, A. B. Lopelove, and S. V. Brayton. 1987 More powerful peroxide Kjeldahl digestion method. J. Assoc. Off. Anal. Chem. 70:783.

Hammon, H. M., and J. W. Blum. 1998. Metabolic and endocrine traits of neonatal calves are influenced by feeding colostrum for different durations or only milk replacer. J. Nutr. 128:624-632.

Herdt, T. H. 2000. Ruminant adaptation to negative energy balance. Influences on the etiology of ketosis and fatty liver. Vet. Clin. North Am. Food Anim. Pract. 16:215-230.

Jørgensen, C. H., R. Spörndly, J. Bertilsson, and S. Østergaard. 2016 Invited review: Carryover effects of early lactation feeding on total lactation performance in dairy cows. J. Dairy Sci. 99:3241-3249.

Karkalas, J. 1985. An improved enzymatic method for the determination of native and modified starch. J. Sci. Food Agric. 36:1019 1027.

Koenig, K. M., K. A. Beauchemin, and L. M. Rode. 2003. Effect of grain processing and silage on microbial protein synthesis and nutrient digestibility in beef cattle fed barley-based diets. J. Anim. Sci. 81:1057-1067.

McCarthy, M. M., T. Yasui, C. M. Ryan, G. D. Mechor, and T. R. Overton. 2015a. Performance of early-lactation dairy cows as affected by dietary starch and monensin supplementation. J. Dairy Sci. 98:3335-3350.

McCarthy, M. M., T. Yasui, C. M. Ryan, S. H. Pelton, G. D. Mechor, and T. R. Overton. 2015b. Metabolism of early-lactation dairy cows as affected by dietary starch and monensin supplementation. J. Dairy Sci. 98:3351-3365.

Mertens, D. R. 2002. Gravimetric determination of amylase-treated neutral detergent fiber in feeds using refluxing in beakers or crucibles: collaborative study. J. AOAC Int. 85:1217-1240.

Nelson, B. H., K. W. Cotanch, M. P. Carter, H. M. Gauthier, R. E. Clark, P. D. Krawczel, R. J. Grant, K. Yagi, K. Fujita, and H. M. Dann. 2011. Effect of dietary starch content in early lactation on the lactational performance of dairy cows. J. Dairy Sci. 94(ESuppl.):637. (Abstr.)

NRC. 2001. Nutrient Requirements of Dairy Cattle. 7th rev. ed. Natl. Acad. Press, Washington, DC. 
Oba, M., and M. S. Allen. 2003a. Effects of corn grain conservation method on feeding behavior and productivity of lactating dairy cows at two dietary starch concentrations. J. Dairy Sci. 86:174183.

Oba, M., and M. S. Allen. 2003b. Dose-response effects of intrauminal infusion of propionate on feeding behavior of lactating cows in early or midlactation. J. Dairy Sci. 86:2922-2931.

Ospina, P. A., D. V. Nydam, T. Stokol, and T. R. Overton. 2010. Association between the proportion of sampled transition cows with increased nonesterified fatty acids and $\beta$ - hydroxybutyrate and disease incidence, pregnancy rate, and milk production at the herd level. J. Dairy Sci. 93:3595-3601.

Piantoni, P., A. L. Lock, and M. S. Allen. 2015b. Saturated fat supplementation interacts with dietary forage neutral detergent fiber content during the immediate postpartum and carryover periods in Holstein cows: Production responses and digestibility of nutrients. J. Dairy Sci. 98:3309-3322.

Piantoni, P., C. M. Ylioja, and M. S. Allen. 2015a. Feed intake is related to changes in plasma nonesterified fatty acid concentration and hepatic acetyl CoA content following feeding in lactating dairy cows. J. Dairy Sci. 98:6839-6847.

Rabelo, E., R. L. Rezende, S. J. Bertics, and R. R. Grummer. 2003. Effects of transition diets varying in dietary energy density on lactation performance and ruminal parameters of dairy cows. J. Dairy Sci. 86:916-925.

Reynolds, C. K., P. C. Aikman, B. Lupoli, D. J. Humphries, and D. E. Beever. 2003. Splanchnic metabolism of dairy cows during the transition from late gestation through early lactation. J. Dairy Sci. $86: 1201-1217$.

Rockwell, R. J., and M. S. Allen. 2016. Chromium propionate supplementation during the peripartum period interacts with starch source fed postpartum: Production responses during the immediate postpartum and carryover periods. J. Dairy Sci. 99:4453-4463.

Sadri, H., G. R. Ghorbani, H. R. Rahmani, A. H. Samie, M. Khorvash, and R. M. Bruckmaier. 2009. Chromium supplementation and substitution of barley grain with corn: Effects on performance and lactation in periparturient dairy cows. J. Dairy Sci. 92:5411-5418.

Sadri, H., H. R. Rahmani, M. Khorvash, G. R. Ghorbani, and R. M. Bruckmaier. 2012. Chromium supplementation and substitution of barley grain with corn: Effects on metabolite and hormonal responses in periparturient dairy cows. J. Anim. Physiol. Anim. Nutr. (Berl.) 96:220-227.

Stocks, S. E., and M. S. Allen. 2012. Hypophagic effects of propionate increase with elevated hepatic acetyl coenzyme A concentration for cows in the early postpartum period. J. Dairy Sci. 95:3259-3268.

Stocks, S. E., and M. S. Allen. 2013. Hypophagic effects of propionic acid are not attenuated during a 3-day infusion in the early postpartum period in Holstein cows. J. Dairy Sci. 96:4615-4623.

Wildman, E. E., G. M. Jones, P. E. Wagner, R. L. Boman, H. F. Troutt Jr., and T. N. Lesch. 1982. A dairy cow body condition scoring system and its relationship to selected production characteristics. J. Dairy Sci. 65:495-501. 